\title{
Pattern of obesity and associated diabetes in Lebanese adolescents: a pilot study
}

\author{
P. Salameh ${ }^{7}$ and B. Barbour ${ }^{1}$
}

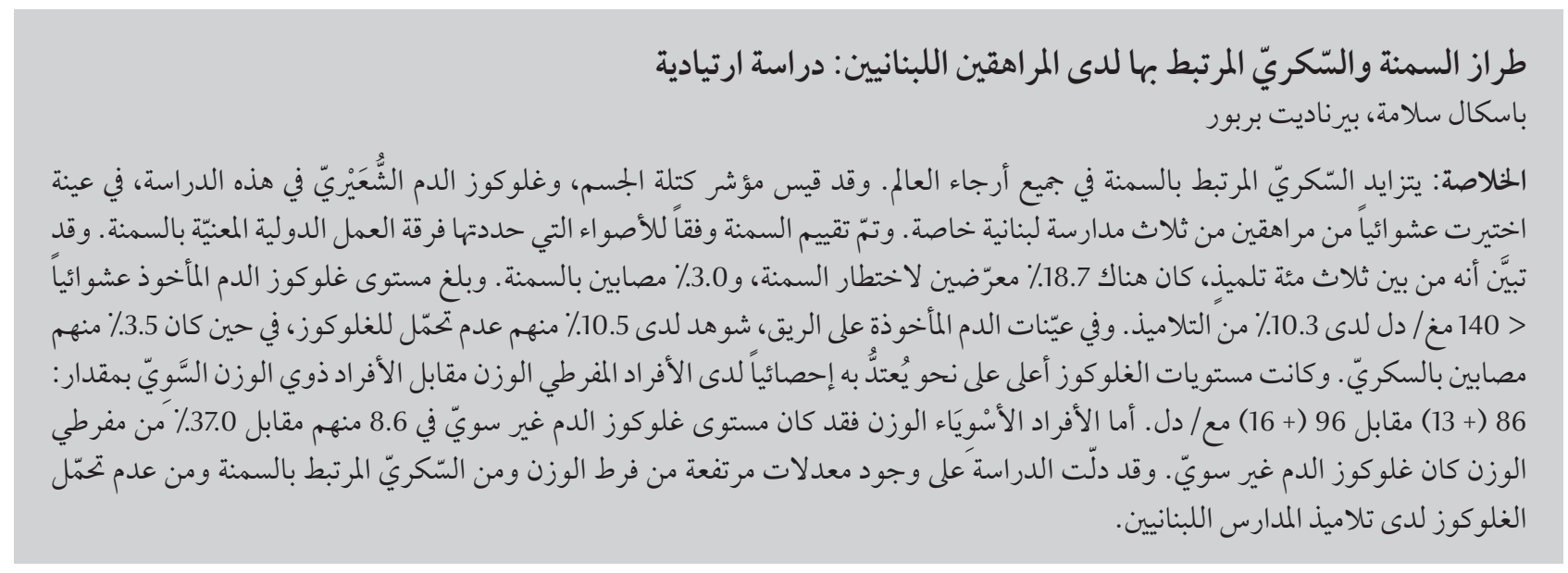

ABSTRACT Obesity-associated diabetes in adolescents is increasing throughout the world. In this study, body mass index and capillary blood glucose were measured in a randomly selected sample of adolescents from 3 Lebanese private schools. Obesity was evaluated according to International Obesity Task Force cut-offs. Out of 300 students, $18.7 \%$ were at risk of obesity and 3.0\% were obese. Random glycaemia level was $\geq 140 \mathrm{mg} / \mathrm{dL}$ in $10.3 \%$ of students. In those fasting, $10.5 \%$ had glucose intolerance and $3.5 \%$ had diabetes. Glucose levels were significantly higher in overweight versus normal weight individuals: 86 (SD 13) versus 96 (SD 16) mg/dL. Among the normal weight group $8.6 \%$ had abnormal glycaemia while among those who were overweight $37.0 \%$ had abnormal glycaemia. Lebanese school students have high rates of overweight and of obesity-associated diabetes and glucose intolerance.

\section{Obésité et diabète associé chez les adolescents libanais : une étude pilote}

RÉSUMÉ Le diabète associée à l'obésité chez les adolescents est en augmentation dans le monde. Dans la présente étude, l'indice de masse corporelle et la glycémie capillaire ont été mesurés dans un échantillon d'adolescents fréquentant trois écoles privées libanaises et sélectionnés au hasard. L'obésité a été évaluée à l'aide des valeurs seuils du Groupe de travail international sur l'obésité (IOTF). Sur 300 élèves, 18,7\% couraient un risque élevé d'obésité et 3,0 \% étaient obèses. La glycémie aléatoire était supérieure ou égale à $140 \mathrm{mg} / \mathrm{dl}$ chez 10,3\% des élèves. Chez les élèves à jeun, 10,5\% souffraient d'une intolérance au glucose et 3,5\% étaient diabétiques. Les taux de glycémie étaient significativement supérieurs chez les enfants en surpoids par rapport aux enfants ayant un poids normal : $86 \mathrm{mg} / \mathrm{dl}$ (E.T. 13) par rapport à 96 mg/dl (E.T. 16). Dans le groupe d'enfants ayant un poids normal, 8,6 \% présentaient un taux de glycémie anormal alors que ce taux était de $37 \%$ chez les élèves en surpoids. Les élèves libanais présentent des taux élevés de surpoids, de diabète associé à l'obésité et d'intolérance au glucose. 


\section{Introduction}

Childhood obesity is increasing worldwide and it has become the most important chronic disease of childhood [1]. Type 2 diabetes mellitus (DM) during childhood and adolescence, first diagnosed among Pima Indians in 1979, is accelerating in parallel [2-7]. In 2000, an alarming increase of childhood type $2 \mathrm{DM}$ among ethnic minorities in the United States was described [2]. Type $2 \mathrm{DM}$ has also been reported among children in Europe [4-6]. The evidence for an association between childhood obesity and type $2 \mathrm{DM}$ is growing [2]. It has been demonstrated that severely obese children and adolescents with impaired glucose tolerance are at very high risk for developing type $2 \mathrm{DM}$ over a short period of time [8].

Lebanon is a developing country in economic transition. However, epidemiological transition too is beginning to appear in the population. We can observe the gradual adoption of developed country lifestyles in terms of eating habits and physical inactivity. In previous studies, in both private $[9,10]$ and public schools [11], Chakar and Salameh demonstrated that childhood obesity was a growing problem in Lebanon, In private schools, $10.1 \%$ of boys were obese and $28.8 \%$ at-risk of obesity (overweight but not yet obese) while $4.2 \%$ of girls were obese and $19.0 \%$ atrisk of obesity $[9,10]$. In public schools, as expected, lower rates were found for boys; $6.7 \%$ were obese and $20.8 \%$ atrisk of obesity, while for girls $6.0 \%$ were obese and $20.3 \%$ at-risk of obesity [11]. The objectives of this pilot study were to investigate the association between obesity and diabetes in Lebanese adolescents attending private schools.

\section{Methods}

\section{Study population}

This was a cross-sectional pilot study performed on adolescent school students attending Lebanese private schools between April and June 2007. School directors of 3 private schools located in an urban area of Mount Lebanon were contacted, and an informed consent form was sent to parents to be signed before the study began. Students aged 11-18 years of age were included in the study. A minimal sample size of 297 students was to be selected, given a prevalence of $5 \%$ and a precision of $2 \%$. Out of the provided lists of students, a random sample of 300 students was selected from the 3 schools. Those reporting an existing diagnosis of DM were excluded and replaced by others.

\section{Data collection}

Short questionnaires were distributed to the students, and they were asked about their sex, age, diabetes-associated symptoms and if they had eaten anything on that day.

A fingerstick blood capillary sample was taken for glycaemia measurement (Accucheck) by 3 trained researchers in collaboration with the school health professional or school director. Random glycaemia (without necessarily fasting) was then classified as normal (< $140 \mathrm{mg} / \mathrm{dL}$ ) or higher than normal ( $\geq$ $140 \mathrm{mg} / \mathrm{dL}$ ), according to the recommendations of Rolka et al. for diabetes screening [12]. Fasting glucose was classified as follows: normal $(<100 \mathrm{mg} /$ $\mathrm{dL})$, prediabetes/glucose intolerance $(100-125 \mathrm{mg} / \mathrm{dL})$ or diabetes $(\geq 125$ $\mathrm{mg} / \mathrm{dL})[13]$.

Students' weight and height were measured using the same calibrated balance (Soehle, sensitivity 500g) and stadiometer for height measurement (Stanley, MABO Microtorse); shoes were removed and measurements were made with light indoor clothing only. Body mass index (BMI) was calculated in $\mathrm{kg} / \mathrm{m} 2$ and used to as a measure of obesity $[14,15]$. As adult cut-off values are not valid for adolescents [16], obesity and at-risk of obesity (i.e. overweight but not yet obese) were defined according to the cut-offs of the International
Obesity Taskforce criteria for BMI of children aged 2-18 years, which for age 18 years pass through the widely used points of $25 \mathrm{~kg} / \mathrm{m} 2$ and $30 \mathrm{~kg} / \mathrm{m} 2$ and for adult overweight and obesity respectively [16]. In this article, we use the term "overweight" to define individuals of higher than normal weight (both obese and at-risk of obesity).

\section{Statistical analysis}

Data entry and analysis were performed using SPSS statistical software, version 11.5. Fisher exact test was used to compare prevalences between age groups and between boys and girls. Student t-test was used to compare between group means and standard deviation (SD) of continuous variables.

\section{Results}

The sample comprised 150 (50.0\%) boys and 150 (50.0\%) girls in the following age groups: 141 (47.0\%) aged $11-14$ years and 159 (53.0\%) aged $15-18$ years.

\section{Obesity and at-risk of obesity}

According to the BMI classification, $18.7 \%$ of students were at-risk of obesity, while $3.0 \%$ were obese. The 11-14year-olds had a higher prevalence of at-risk of obesity than the 15-18-yearolds (23.4\% versus $14.5 \%)$ but this did not reach statistical significance $(P=$ 0.092). Compared with girls, boys had significantly higher rates of obesity (4.7\% versus $1.3 \%$ ) and at-risk of obesity $(26.7 \%$ versus $10.7 \%)(P<0.001)$ (Table 1).

In stratified analysis, there were no significant differences in the proportions who were overweight between the 2 age groups of boys, whereas for girls the rate of overweight (obese plus at-risk of obesity) was $17.8 \%$ in girls $11-14$ years old versus $6.5 \%$ in those aged $15-18$ years old $(P=0.005)($ Table 1$)$. 


\begin{tabular}{|c|c|c|c|c|c|c|}
\hline \multirow[t]{2}{*}{ Characteristic } & Total & Normal & $\begin{array}{l}\text { At-risk of } \\
\text { obesity }\end{array}$ & Obese & $P$-value ${ }^{a}$ & $\begin{array}{c}\text { OR }(95 \% \mathrm{Cl}) \text { for } \\
\text { overweight }\end{array}$ \\
\hline & No. & $\%$ & $\%$ & $\%$ & & \\
\hline Sex & & & & & $<0.001$ & $3.3(1.8-6.1)$ \\
\hline Male & 150 & 68.7 & 26.7 & 4.7 & & \\
\hline Female & 150 & 88.0 & 10.7 & 1.3 & & \\
\hline Age (years) & & & & & 0.092 & $1.7(0.95-2.9)$ \\
\hline $11-14$ & 141 & 73.8 & 23.4 & 2.8 & & \\
\hline $15-18$ & 159 & 82.4 & 14.5 & 3.1 & & \\
\hline Boys (years) & & & & & 0.585 & $1.4(0.7-2.8)$ \\
\hline 11-14 & 68 & 64.7 & 29.4 & 5.9 & & \\
\hline $15-18$ & 82 & 72.0 & 24.4 & 3.7 & & \\
\hline Girls (years) & & & & & 0.005 & $3.1(1.1-9.3)$ \\
\hline $11-14$ & 73 & 82.2 & 17.8 & 0.0 & & \\
\hline $15-18$ & 77 & 93.5 & 3.9 & 2.6 & & \\
\hline Total & 300 & 78.3 & 18.7 & 3.0 & NA & \\
\hline
\end{tabular}

${ }^{a}$ For differences in overweight between groups (obese plus at-risk of obesity).

$O R=$ odds ratio; $C I=$ confidence interval; $N A=$ not applicable.

\section{Glycaemia, diabetes and obesity status}

Out of 300 students, 31 (10.3\%; 95\% CI: $7.1 \%-14.3 \%)$ had a random capillary blood glucose level $\geq 140 \mathrm{mg} / \mathrm{dL}$. Of 143 students reporting that they were fasting on the day of the study, 123 (86.0\%, 95\% CI: $80.3 \%-91.7 \%)$ had a fasting glucose level $<100 \mathrm{mg} / \mathrm{dL}$ (normal) 15 (10.5\%, 95\% CI: $5.0 \%-15.5 \%)$ had glucose
$100-125 \mathrm{mg} / \mathrm{dL}$ (glucose intolerance) and 5 (3.5\%, 95\% CI: $1.1 \%-8.0 \%)$ had glucose $\geq 125 \mathrm{mg} / \mathrm{dL}$ (diabetes).

Figure 1 shows the association between overweight and diabetes status. There was a significant increase in the risk of prediabetes (29.6\%, relative risk $=4.93)$ and diabetes (7.4\%, relative risk $=2.85)$ in overweight versus normal weight students $(P=0.001)$.
Table 2 presents the diabetes-associated symptoms reported by students. Suffering from at least 1 chronic symptom, in particular blurred vision and slow wound healing, was significantly associated with a random capillary glucose level $\geq 140 \mathrm{mg} / \mathrm{dL}(P=0.001)$. No statistically significant differences between boys and girls were found for diabetes-associated symptoms.

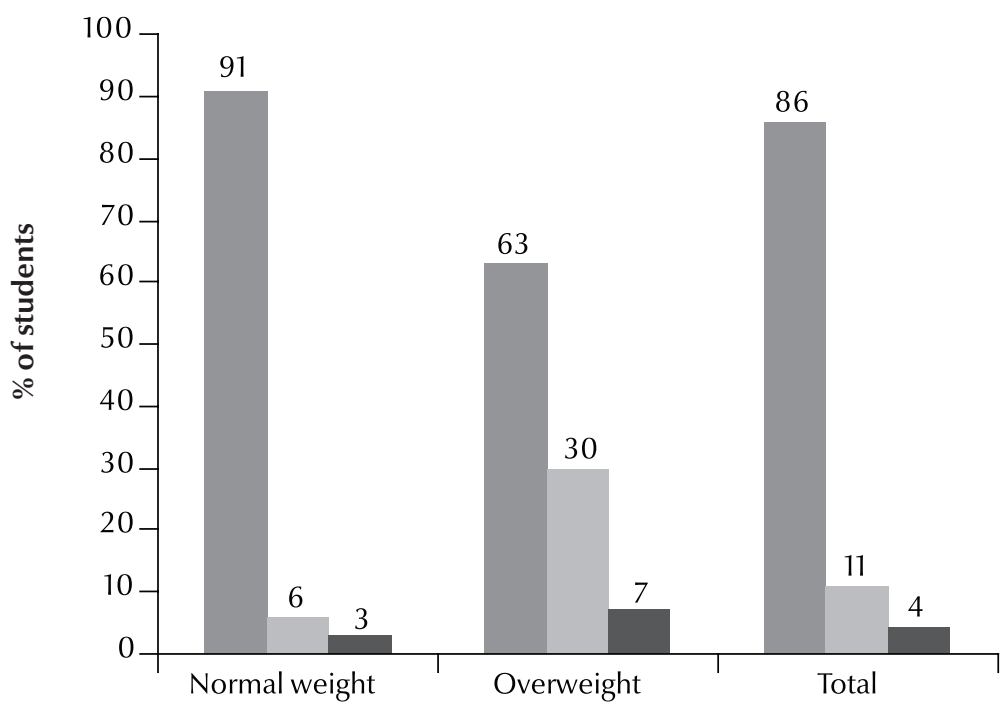

Normal fasting glucose

Prediabetes

Diabetes

Figure 1 Prevalence of prediabetes and diabetes in normal weight and overweight students (obese plus at-risk of obesity) $(P<0.001)$ 


\begin{tabular}{|c|c|c|c|c|c|c|c|}
\hline \multirow[t]{2}{*}{ Symptoms } & \multicolumn{2}{|c|}{$\begin{array}{c}\text { Total } \\
(n=298)\end{array}$} & \multicolumn{2}{|c|}{$\begin{array}{l}\text { Normal glucose } \\
\quad(n=268)\end{array}$} & \multicolumn{2}{|c|}{$\begin{array}{c}\text { Glucose } \geq 140 \mathrm{mg} / \mathrm{dL} \\
(n=31)\end{array}$} & \multirow[t]{2}{*}{$P$-value } \\
\hline & No. & $\%$ & No. & $\%$ & No. & $\%$ & \\
\hline Polyphagia & 104 & 34.9 & 93 & 34.7 & 11 & 35.5 & 0.94 \\
\hline Polyuria/polydypsia & 84 & 28.2 & 72 & 26.9 & 12 & 38.7 & 0.16 \\
\hline Headache & 58 & 19.5 & 49 & 18.3 & 9 & 29.0 & 0.15 \\
\hline Shaking & 39 & 13.1 & 32 & 11.9 & 7 & 22.6 & 0.15 \\
\hline Slow wound healing & 46 & 15.4 & 37 & 13.8 & 9 & 29.0 & 0.03 \\
\hline Blurred vision & 85 & 28.5 & 69 & 25.7 & 16 & 51.6 & 0.003 \\
\hline At least 1 symptom & 197 & 66.1 & 168 & 62.7 & 29 & 93.5 & 0.001 \\
\hline
\end{tabular}

Mean random capillary glucose levels were significantly higher in overweight than normal weight students: 96 (SD 16) versus $86($ SD 13) mg/ $\mathrm{dL}(P<0.001)$. In addition, $8.6 \%$ of the normal weight group had abnormal glycaemia while $37.0 \%$ of those who were overweight had abnormal glycaemia $(P$ $<0.001$ ).

\section{Discussion}

In this study we found high rates of adolescents, particularly boys, suffering from overweight. We also found alarming rates of abnormal random and fasting glycaemia. Capillary blood glucose levels were significantly higher in students who were overweight than those who were normal weight. Three years after the 2005 study, the pattern of obesity and at-risk of obesity in Lebanese private schools and the differences between boys and girls are the same; boys were more obese than girls, and age differences in obesity were significant only in girls, with higher ages associated with lower rates of overweight $[9,10]$. Our results are also comparable to those of Sebai et al. in Lebanon for boys and girls: $22.5 \%$ versus $16.1 \%$ for overweight and $7.5 \%$ versus $3.2 \%$ for obesity respectively [17]. They are also comparable to those reported for the USA population, with rates of obesity of $10.9 \%$ and at-risk of obesity of $22 \%$ in children aged 6-17 years [18].
The rates of diabetes were somewhat higher than those found elsewhere in the world for children and adolescents [2-6]. Pearson et al. performed a similar study in Copenhagen schools and found similar patterns of obesity and overweight, although few students had abnormal glycaemia [19]. In addition, the SEARCH for Diabetes in Youth study group in the year 2001 estimated the overall prevalence of type 2 diabetes in youth aged 10-19 years as 0.42 per 1000 (95\% CI: $0.39-0.45)$, with considerable variability across race/ ethnic groups [20]. These figures are different from those reported by the Third National Health and Nutrition Examination Survey; their estimated prevalence of diabetes per 100 adolescents aged $12-19$ years was $0.41 \%$ (95\% CI: $0 \%-0.86 \%)$. The prevalence of impaired fasting glucose $(\geq 6.1 \mathrm{mmol} / \mathrm{L})$ among adolescents without diabetes who had fasted for at least $8 \mathrm{~h}$ was $1.76 \%$ (95\% CI: $0.02 \%-3.50 \%$ ) [21].

Another study in the Middle East found a prevalence of impaired glucose tolerance tests of $0.25 \%$ in individuals $<14$ years and $0.21 \%$ in those $14-29$ years. It also found a diabetes prevalence of $0.12 \%$ and $0.79 \%$ respectively in these age groups [22]. Our results of $10.5 \%$ for impaired glucose and $3.5 \%$ for hyperglycaemia are much higher than those reported in developed or developing countries [22,23]. This suggests that immediate interventions are needed in adolescents in Lebanese schools to diagnose and treat DM.

All the cases of diabetes were previously undiagnosed, since having diabetes was an exclusion criterion, but we could not make a specific diagnosis for diabetes, to know if it was type 1 or type 2 DM. However, since glycaemia abnormalities were more common in overweight individuals and the symptoms presented by these adolescents (such as slow wound healing, blurred vision) were not severe enough to stimulate immediate help-seeking, we have reason to believe that they had impaired glucose tolerance or hyperglycaemia caused by higher insulin resistance associated with type $2 \mathrm{DM}[24,25]$. In fact, insulin resistance is a common feature of childhood obesity and is considered to be an important link between adiposity and the associated risk of type $2 \mathrm{DM}$, metabolic syndrome and cardiovascular disease. Several factors are implicated in the pathogenesis of obesity-related insulin resistance, such as increased free fatty acids and hormones and cytokines released by adipose tissue [26].

In addition, there is a possibility of a non-differential classification bias, since the apparatus we used to measure glycaemia may be less sensitive or specific than regular laboratory measurements. While we have no reason to believe that the results would change if we use more accurate tests, there is a possibility of improvements in sensitivity [12] that 
could provide higher estimates of the prevalence of diabetes.

Nevertheless, further larger-scale studies are needed to confirm the findings of this pilot study and provide more evidence of the need to assess and diagnose diabetes in the Lebanese adolescent population.
In the meantime, prevention of type $2 \mathrm{DM}$ by healthy eating habits and physical activity education are necessary for all adolescents [13]. Screening should also be regularly performed according to worldwide recommendations, such as those of the American Diabetes Association [27].
In conclusion, we found high rates of both obesity and diabetes; therefore, diagnosis and treatment of both these problems in Lebanon should be a priority for children and adolescents and should be offered to individuals who need it.

\section{References}

1. Dietz WH. Overweight in childhood and adolescence. New England Journal of Medicine, 2004, 350:855-857.

2. Fagot-Campagna A. Emergence of type 2 diabetes mellitus in children: epidemiological evidence. Journal of Pediatric Endocrinology \& Metabolism, 2000, 13(Suppl, 6):1395-1402.

3. Savage PJ et al. High prevalence of diabetes in young Pima Indians: evidence of phenotypic variation in a genetically isolated population. Diabetes, 1979, 28:937-942.

4. Drake AJ et al. Type 2 diabetes in obese white children. $A r$ chives of Disease in Childhood, 2002, 86:207-208.

5. Wabitsch $\mathrm{M}$ et al. Type II diabetes mellitus and impaired glucose regulation in Caucasian children and adolescents with obesity living in Germany. International Journal of Obesity, 2004, 28:307-313.

6. Malecka-Tendera E, Erhardt E, Molnar D. Type 2 diabetes mellitus in European children and adolescents. Acta Paediatrica 2005, 94:543-546.

7. Nathan BM, Moran A. Metabolic complications of obesity in childhood and adolescence: more than just diabetes. Current Opinion in Endocrinology, Diabetes, and Obesity, 2008, 15:21-29.

8. Weiss R et al. Predictors of changes in glucose tolerance status in obese youth. Diabetes Care, 2005, 28:902-909.

9. Chakar H, Salameh P. Growth and obesity in Lebanese private schools children. Le Journal Medical Libanais, 2007, 55:75-82.

10. Chakar H, Salameh P. Obesity in Lebanese private schools adolescents. European Journal of Public Health, 2006, 16(6):648651.

11. Chakar H, Salameh P. Growth and obesity in Lebanese public schools adolescents. Lebanese Medical Journal (Article accepted for publication).

12. Rolka DB et al. Performance of recommended screening tests for undiagnosed diabetes and dysglycemia. Diabetes Care, 2001, 24:1899-1903.

13. Schwartz MS, Chadha A. Type 2 diabetes mellitus in childhood: obesity and insulin resistance. Journal of the American Osteopathic Association, 2008, 108:518-524.

14. Magarey AM et al. Predicting obesity in early adulthood from childhood and parental obesity. International Journal of Obesity and Related Metabolic Disorders, 2003, 27:505-513.
15. Luciano A et al. Definition of obesity in childhood: criteria and limits. Minerva Pediatrica, 2003, 55:453-459.

16. Cole TJ et al. Establishing a standard definition for child overweight and obesity worldwide: international survey. British Medical Journal, 2000, 320:1240-1243.

17. Sibai AM et al. Prevalence and covariates of obesity in Lebanon: findings from the first epidemiological study. Obesity Research, 2003, 11:1353-1361.

18. Styne D. Childhood and adolescent obesity. Prevalence and significance. Pediatric Clinics of North America, 2001, 48:823-854

19. Pearson $\mathrm{S}$ et al. Screening Copenhagen school children at risk of type 2 diabetes mellitus using random capillary blood glucose. Acta Paediatrica (Oslo, Norway), 2007, 96:885-889.

20. SEARCH for Diabetes in Youth Study Group. The burden of diabetes mellitus among US youth: prevalence estimates from the SEARCH for Diabetes in Youth Study. Pediatrics, 2006, 118:1510-1518.

21. Fagot-Campagna A et al.; Third National Health and Nutrition Examination Survey. Diabetes, impaired fasting glucose, and elevated HbAlc in U.S. adolescents: the Third National Health and Nutrition Examination Survey. Diabetes Care, 2001, 24:834-837.

22. El-Hazmi MA, Warsy AS. Prevalence of overweight and obesity in diabetic and non-diabetic Saudis. Eastern Mediterranean Health Journal, 2000, 6:276-282.

23. Singh R, Shaw J, Zimmet P. Epidemiology of childhood type 2 diabetes in the developing world. Pediatric Diabetes, 2004, 5:154-168.

24. Caprio $S$ et al. Early phase insulin secretion is normal in obese adolescents with impaired glucose tolerance (IGT). Program and abstracts of the 61st Scientific Sessions of the American Diabetes Association; June 22-26, 2001; Philadelphia, Pennsylvania. Diabetes, 2001, 50(Suppl. 2):Abstract 224OR.

25. Botero D, Wolfsdorf JI. Diabetes mellitus in children and adolescents. Archives of Medical Research, 2005, 36:281-290.

26. Chiarelli F, Marcovecchio ML. Insulin resistance and obesity in childhood. European Journal of Endocrinology, 2008, 159(Suppl. 1):S67-S74.

27. American Diabetes Association. Type 2 diabetes in children and adolescents. Diabetes Care, 2000, 23:381-389. 